\title{
Comparison of haemodynamic effects of oral prazosin, oral hydralazine, and intravenous nitroprusside in same patients with chronic heart failure ${ }^{1}$
}

\author{
JAWAHAR MEHTA, MARIE IACONA, CARL J. PEPINE, AND \\ C. RICHARD CONTI \\ From the Cardiology Section, Veterans Administration Medical Center and Division of Cardiology, \\ Department of Medicine, College of Medicine, Gainesville, Florida, USA
}

SUMMARY The haemodynamic effects of oral prazosin and hydralazine were evaluated in patients with refractory heart failure and compared with those of intravenous nitroprusside in the same patients. Both oral agents were well tolerated and appeared to have beneficial haemodynamic effects. Prazosin and hydralazine produced similar increases in cardiac output associated with a similar decrease in systemic vascular resistance. Prazosin resulted in a more significant decline in left ventricular filling pressure and pulmonary vascular resistance than did hydralazine. Haemodynamic alterations induced by prazosin were similar to those induced by nitroprusside, which suggests a relatively balanced reduction of preload and afterload. With hydralazine, the increase in cardiac output without change in left ventricular filling pressure or pulmonary vascular resistance suggests minimal effect on preload but significant reduction in afterload.

A decrease in left ventricular afterload in patients with heart failure improves left ventricular function by increasing stroke volume and decreasing left ventricular filling pressure (Franciosa et al., 1972; Chatterjee et al., 1973a; Guiha et al., 1974). This has been shown in heart failure associated with a variety of pathological states, such as coronary heart disease (Franciosa et al., 1972; Chatterjee et al., 1973a), mitral and aortic regurgitation (Chatterjee et al., 1973b; Bolen and Alderman, 1976), and hypertensive heart disease (Majid et al., 1971). Reduction of preload lowers left ventricular filling pressure but does not consistently result in increased stroke volume (Franciosa et al., 1974; Mantle et al., 1976).

Intravenously administered nitroprusside produces a rapid increase in cardiac output and fall in left ventricular filling pressure in certain patients with heart failure as a result of afterload and preload reduction. Because nitroprusside must be given parenterally, its usefulness is limited to patients in hospital. Thus, it would be clinically useful if oral agents with a similar mode of action were available to increase stroke volume and decrease pulmonary

'Presented in part at the Annual Scientific Session of the American College of Cardiology, Anaheim, California, March 1978.

Received for publication 6 June 1979 congestion in patients with heart failure. In ambulant patients with heart failure, both hydralazine (Chatterjee et al., 1976b; Franciosa et al., 1977; Mehta et al., 1978b) and prazosin (Awan et al., 1977; Mehta et al., 1978a) have shown promise in preliminary studies. However, in individual patients with heart failure, the haemodynamic response to vasodilators can vary (Chatterjee and Parmley, 1977). We therefore compared the haemodynamic and clinical effects of various vasodilator agents in the same patients. This study was designed so that the effects of two oral vasodilator agents, hydralazine and prazosin, could be evaluated, and the effects of these compared with those induced by intravenous nitroprusside in the same patients.

\section{Patients and methods}

The subjects were 11 male patients, aged 37 to 65 years, with symptoms and signs of clinical heart failure (New York Heart Association class III or IV) despite treatment with digitalis, diuretics, and salt restriction. The duration of heart failure ranged from 3 to 7 years before study. In all, heart failure was the result of coronary heart disease, documented by history, electrocardiogram, and previous coronary angiography. None complained of angina pectoris at the time of study. Each of these patients 
had areas of abnormal left ventricular wall motion observed during left ventriculography, and all had an enlarged heart. A left ventricular diastolic gallop was heard in seven patients. Basal râles were present in seven. All patients were in sinus rhythm, though three had occasional atrial or ventricular ectopic beats. These clinical observations were made before haemodynamic study.

\section{HAEMODYNAMIC STUDIES}

The procedure and drugs to be used were explained to the patients, and their informed consent was given. Investigations were performed in a special study room of the cardiac care unit, so that haemodynamic variables could be monitored and recorded for the duration of study. Digitalis was continued, but diuretic agents (hydrochlorothiazide $50 \mathrm{mg}$ daily in six patients and frusemide $40 \mathrm{mg}$ daily in the other five) and nitrates were withheld for two days before study. These agents were discontinued so that haemodynamic variables were affected primarily by the study drugs rather than the acute effects of diuretics and nitrates. The patients were kept at bed-rest for at least eight hours before and throughout the study period. A triple lumen flowdirected catheter was advanced to the pulmonary artery, and a 'teflon' catheter was introduced percutaneously into the radial artery to measure systemic blood pressure. Systemic and pulmonary arterial pressures and pulmonary artery wedge pressure were recorded on a VR-6 recorder (Electronics for Medicine, White Plains, NY) with Statham P23Ia strain gauge transducers. Systolic and diastolic pressures were averaged from at least 10 beats measured over two respiratory cycles. Mean pressures were obtained by electronic filtration. The occluded pulmonary artery pressure recorded during balloon inflation was taken as pulmonary artery wedge pressure and agreed closely with pulmonary artery diastolic pressure in each patient; either of these measurements was used as an index of left ventricular filling pressure. All pressure measurements were recorded with reference to midchest zero with the patient supine. Heart rate was averaged from recordings of a standard electrocardiographic lead. Cardiac output was measured in triplicate by thermodilution (Ganz and Swan, 1972) and reported as the average of these three determinations.

The following calculations were made:

CI $\left(1 / \mathrm{min}\right.$ per $\left.\mathrm{m}^{2}\right)=\mathrm{CO} / \mathrm{BSA}$

$\mathrm{SV}(\mathrm{ml} / \mathrm{beat})=\mathrm{CO} / \mathrm{HR}$

SVI $\left(\mathrm{ml} /\right.$ beat per $\left.\mathrm{m}^{2}\right)=S V / B S A$

LVSWI $\left(\mathrm{g} \mathrm{m} / \mathrm{m}^{2}\right)=$ SVI $\times(\overline{\text { Ao-LVFP }}) \times 0.0136$

SVR (dynes s cm${ }^{-5}$ ) $=\overline{\mathrm{Ao}} \times 80 / \mathrm{CO}$

PVR $\left(\right.$ dynes s cm$\left.{ }^{-b}\right)=(\overline{\mathrm{PA}}-\mathrm{LVFP}) \times 80 / \mathrm{CO}$
Index of myocardial oxygen demand $=S A P \times H R$. (Abbreviations: $\mathrm{CI}$, cardiac index: $\mathrm{CO}$, cardiac output; BSA, body surface area; SV, stroke volume; HR, heart rate; LVSWI, left ventricular stroke work index; SVI, stroke volume index; $\overline{\mathrm{Ao}}$, arterial mean pressure; LVFP, left ventricular filling pressure; SVR, systemic vascular resistance; PVR, pulmonary vascular resistance; $\overline{\mathrm{PA}}$, pulmonary arterial mean pressure; and $\mathrm{SAP}$, arterial systolic pressure.

Patients were evaluated clinically during the control period and hourly during drug administration.

\section{STUDY PROCEDURE}

\section{General design}

Before each of the three drug study periods, control haemodynamic recordings were obtained during a haemodynamically stable interval when pressures, cardiac output, and heart rate were unchanged $( \pm 10 \%)$ from initial baseline values over 30 minutes with repeated measurements. Haemodynamic recordings were then repeated during drug administration. These recordings included heart rate, systemic and pulmonary artery pressures, and cardiac output.

\section{Nitroprusside administration}

Nitroprusside was given by an infusion pump into a peripheral vein starting at $10 \mu \mathrm{g} / \mathrm{min}$. The infusion rate was increased by $10 \mu \mathrm{g} / \mathrm{min}$ increments every 10 minutes until either left ventricular filling pressure fell to $15 \mathrm{mmHg}$ or less, cardiac output increased by 50 per cent or more, or systolic arterial pressure fell by $20 \mathrm{mmHg}$ or more from the control value or to $100 \mathrm{mmHg}$. Haemodynamic measurements, outlined above, were made at each increment in dose. Nitroprusside infusion was then discontinued.

\section{Prazosin administration}

After re-establishment of a stable control interval, as noted above, $4 \mathrm{mg}$ prazosin was administered orally. Haemodynamic measurements were made every hour for eight hours.

\section{Hydralazine administration}

After haemodynamically stable values were reestablished, similar to those before nitroprusside or prazosin (Table 1), $100 \mathrm{mg}$ hydralazine was administered orally. Haemodynamic measurements were made hourly for eight hours.

The order of the administration of the three vasodilators is shown in Table 1 . Prazosin and nitroprusside were given in random order, but hydralazine was given to only seven patients who agreed to participate in the final phase of the study. 
Table 1 Order of drug administration

\begin{tabular}{llll}
\hline Case no. & \multicolumn{3}{l}{ Drug study period } \\
\cline { 2 - 4 } & $I$ & $I I$ & $I I I$ \\
\hline 1 & NP & P & H \\
2 & NP & P & H \\
3 & NP & P & - \\
4 & NP & P & - \\
5 & NP & P & - \\
6 & P & NP & H \\
7 & P & NP & H \\
8 & P & NP & H \\
9 & P & NP & H \\
10 & P & NP & - \\
11 & P & & \\
\hline
\end{tabular}

Abbreviations: NP, intravenous nitroprusside; $\mathrm{P}$, oral prazosin (4 mg); $\mathrm{H}$, oral hydralazine (100 mg).

\section{Data analysis}

Mean values and standard error of the mean were calculated during each control and treatment period. Mean values in the control state and at the peak effect of each drug were compared. To test for the interaction, the repeated measures analysis of variance model was used. For the purpose of comparison of three drugs, in the seven patients who received all three drugs, Duncan's multiple com- parison test was employed (Winer, 1971). A P value less than 0.05 was considered statistically significant.

\section{Results}

\section{CONTROL STATE}

All haemodynamic variables were comparable in the control state before administration of the three drugs.

\section{PEAK EFFECT}

Maximal change in haemodynamic variables observed with nitroprusside, prazosin, and hydralazine are presented in Table 2.

The effects of nitroprusside were apparent soon after infusion was started and abated when the infusion was discontinued. The change in haemodynamic variables occurred half to one hour after prazosin administration and lasted for six hours. In all patients given hydralazine, the alteration in haemodynamics induced by nitroprusside or prazosin had abated and haemodynamics returned to control levels (Table 2). The interval between prazosin and hydralazine administration varied from 10 to 18 hours (mean 12 hours). The effects of

Table 2 Haemodynamic effects of nitroprusside, prazosin, and hydralazine in heart failure patients

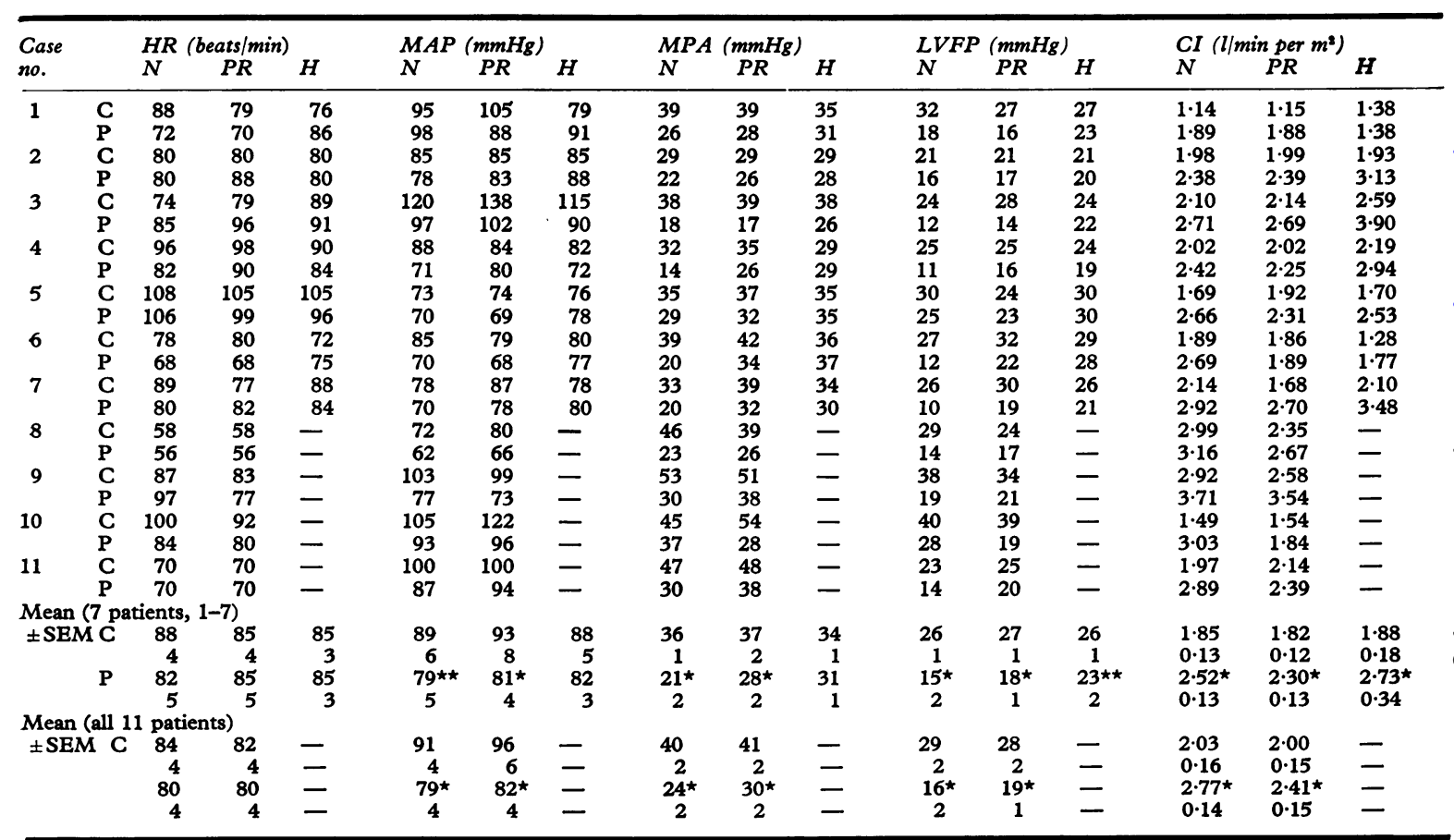

Abbreviations: N, IV nitroprusside; PR, prazosin; H, hydralazine; HR, heart rate; MAP, systemic arterial mean pressure; MPA, pulmonary artery mean pressure; LVFP, left ventricular filling pressure; CI, cardiac index; LVSWI, left ventricular stroke work index; SVR, systemic yascular resistance; $P V R$, pulmonary vascular resistance; $C$, control; $P$, peak effect; ${ }^{\star} P<0.01$ (peak vs control).; $\star \star P<0^{*} 02$ (peak vs control). 
hydralazine were observed at three hours and persisted for eight hours.

Nitroprusside and oral prazosin produced significant increases in cardiac index and left ventricular stroke work. Both agents decreased mean arterial, pulmonary arterial, and left ventricular filling pressures, and systemic and pulmonary vascular resistances. Heart rate was unchanged. Oral hydralazine administration significantly increased cardiac index and left ventricular stroke work, and decreased systemic vascular resistance and left ventricular filling pressure. Hydralazine did not affect heart rate, systemic and pulmonary arterial pressures, pulmonary vascular resistance, or systolic arterial pressure-heart rate product.

\section{NITROPRUSSIDE VS PRAZOSIN}

Comparison of the effects of these two vasodilator agents in all patients showed that they induced a similar increase in cardiac index $(0.74 \pm 0.11$ vs $0.47 \pm 0.091 / \mathrm{min}$ per $\mathrm{m}^{2}$, NS) and a fall in left ventricular filling pressure $(11 \pm 2$ vs $10 \pm 2 \mathrm{mmHg}$, NS). The fall in resistance in the systemic (791 \pm 150 vs $640 \pm 165$ dynes $\mathrm{s} \mathrm{cm}^{-5}$ ) and pulmonary vascular $\left(98 \pm 29\right.$ vs $96 \pm 24$ dynes $\mathrm{s} \mathrm{cm}^{-5}$ ) beds was comparable (NS), as was the decrease in heart rate ( $3 \pm 3$ vs $2 \pm 3$ beats/min), arterial mean $(12 \pm 3$ vs

\begin{tabular}{|c|c|c|c|c|c|c|c|c|}
\hline \multicolumn{3}{|c|}{$\begin{array}{l}L V S W I\left(g \text { mer } m^{2}\right) \\
N \quad P R \quad H\end{array}$} & $\begin{array}{l}S V R \\
N\end{array}$ & $\begin{array}{l}\text { dynes s c } \\
P R\end{array}$ & $\left.m^{-5}\right)$ & \multicolumn{2}{|c|}{$P V R$ (dynes s $\mathrm{cm}^{-5}$ ) } & $\begin{array}{l}\left.\mathrm{cm}^{-5}\right) \\
H\end{array}$ \\
\hline $\begin{array}{r}11 \cdot 10 \\
28 \cdot 56 \\
21 \cdot 54 \\
25 \cdot 08 \\
37 \cdot 05 \\
36 \cdot 86 \\
18 \cdot 03 \\
24 \cdot 08 \\
9 \cdot 15 \\
15 \cdot 36 \\
19 \cdot 11 \\
31 \cdot 20 \\
17 \cdot 00 \\
29 \cdot 78 \\
30 \cdot 14 \\
36 \cdot 83 \\
29 \cdot 67 \\
30 \cdot 17 \\
13 \cdot 17 \\
31 \cdot 89 \\
29 \cdot 47 \\
40.99\end{array}$ & $\begin{array}{l}15 \cdot 44 \\
26 \cdot 29 \\
21 \cdot 65 \\
24 \cdot 38 \\
40 \cdot 52 \\
33 \cdot 54 \\
16 \cdot 54 \\
21 \cdot 76 \\
12 \cdot 43 \\
14 \cdot 60 \\
14 \cdot 86 \\
17 \cdot 39 \\
16 \cdot 91 \\
26 \cdot 42 \\
30 \cdot 86 \\
31 \cdot 77 \\
27 \cdot 48 \\
32 \cdot 51 \\
18 \cdot 90 \\
24 \cdot 09 \\
31 \cdot 18 \\
34 \cdot 36\end{array}$ & $\begin{array}{l}17 \cdot 29 \\
14 \cdot 84 \\
20 \cdot 99 \\
36 \cdot 18 \\
36 \cdot 01 \\
39 \cdot 63 \\
19 \cdot 19 \\
25 \cdot 23 \\
10 \cdot 12 \\
17 \cdot 20 \\
12 \cdot 33 \\
15 \cdot 73 \\
16 \cdot 88 \\
33 \cdot 24 \\
- \\
- \\
- \\
-\end{array}$ & $\begin{array}{r}3160 \\
1966 \\
1908 \\
1456 \\
2078 \\
1301 \\
1958 \\
1319 \\
1899 \\
1644 \\
2194 \\
1269 \\
1389 \\
913 \\
1030 \\
839 \\
1585 \\
932 \\
2805 \\
1221 \\
2030 \\
1204\end{array}$ & $\begin{array}{r}3462 \\
1774 \\
1898 \\
1543 \\
2344 \\
1379 \\
1868 \\
1598 \\
1694 \\
1869 \\
2072 \\
1755 \\
1973 \\
1101 \\
1456 \\
1058 \\
1726 \\
927 \\
3153 \\
2076 \\
1869 \\
1573\end{array}$ & $\begin{array}{r}2665 \\
2500 \\
1957 \\
1249 \\
1615 \\
839 \\
1682 \\
1101 \\
1965 \\
1927 \\
3049 \\
2122 \\
1414 \\
876 \\
- \\
- \\
- \\
- \\
-\end{array}$ & $\begin{array}{r}233 \\
160 \\
180 \\
112 \\
242 \\
81 \\
156 \\
56 \\
130 \\
94 \\
310 \\
145 \\
125 \\
130 \\
243 \\
122 \\
231 \\
133 \\
134 \\
118 \\
487 \\
221\end{array}$ & $\begin{array}{r}396 \\
242 \\
179 \\
167 \\
187 \\
41 \\
222 \\
200 \\
297 \\
244 \\
262 \\
310 \\
204 \\
183 \\
273 \\
144 \\
296 \\
216 \\
388 \\
195 \\
430 \\
301\end{array}$ & $\begin{array}{r}220 \\
220 \\
184 \\
113 \\
197 \\
37 \\
103 \\
153 \\
129 \\
124 \\
419 \\
248 \\
145 \\
99 \\
- \\
- \\
- \\
- \\
- \\
-\end{array}$ \\
\hline $\begin{array}{c}19 \cdot 00 \\
3 \cdot 44 \\
27 \cdot 28^{\star} \\
2 \cdot 55\end{array}$ & $\begin{array}{c}19 \cdot 77 \\
3.62 \\
23 \cdot 48 \star \\
2 \cdot 38\end{array}$ & $\begin{array}{c}18.98 \\
3.18 \\
26.01 \star \\
3.93\end{array}$ & $\begin{array}{c}2084 \\
203 \\
1410^{\star} \\
125\end{array}$ & $\begin{array}{c}2187 \\
226 \\
1574^{\star} \\
100\end{array}$ & $\begin{array}{c}2050 \\
225 \\
1516^{\star} \\
250\end{array}$ & $\begin{array}{c}196 \\
26 \\
111^{\star} \\
14\end{array}$ & $\begin{array}{c}250 \\
29 \\
198^{\star} \\
32\end{array}$ & $\begin{array}{r}200 \\
40 \\
142 \\
27\end{array}$ \\
\hline $\begin{array}{c}21 \cdot 40 \\
2 \cdot 72 \\
30 \cdot 07 \star \\
2 \cdot 12\end{array}$ & $\begin{array}{c}22 \cdot 43 \\
2.67 \\
26 \cdot 10^{\star} \\
1.97\end{array}$ & $\overline{-}$ & $\begin{array}{c}2003 \\
179 \\
1279 \star \\
100\end{array}$ & $\begin{array}{c}3138 \\
188 \\
1514^{\star} \\
110\end{array}$ & - & $\begin{array}{c}225 \\
32 \\
125 \star \\
13\end{array}$ & $\begin{array}{c}285 \\
26 \\
204^{\star} \\
23\end{array}$ & $\frac{-}{-}$ \\
\hline
\end{tabular}

\section{PRAZOSIN VS HYDRALAZINE}

Comparison of the haemodynamic effects of the two oral agents in the same patients showed that cardiac

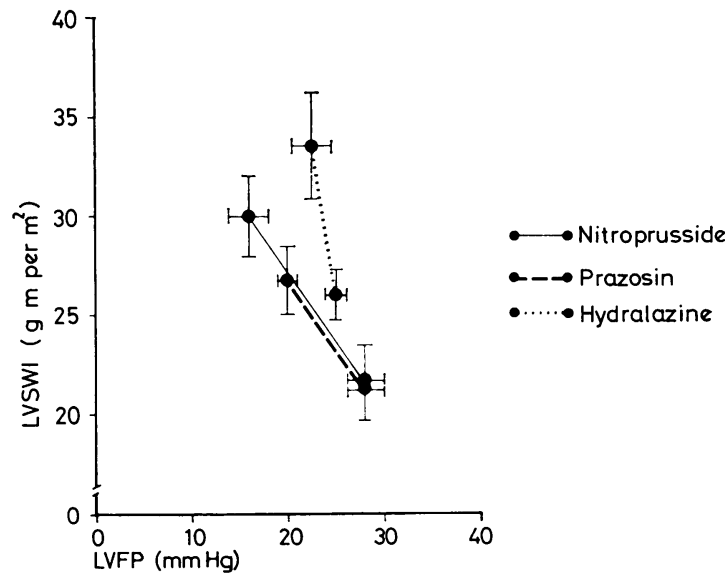

Fig. Effect of intravenous nitroprusside, oral prazosin, and hydralazine on the relation between left ventricular filling pressure (LVFP) and left ventricular stroke work index (LVSWI) in patients with heart failure. Intravenous nitroprusside and prazosin have similar action on the LVFP LVSWI relation, whereas hydralazine increases $L V S W I$ without affecting $L V F P$. 
index increased similarly $(0.48 \pm 0.09$ vs $0.85 \pm 0.19$ $1 / \mathrm{min}$ per $\mathrm{m}^{2}$, NS) with prazosin and with hydralazine. However, left ventricular filling pressure fell more with prazosin than with hydralazine $(8 \pm 2$ vs $3 \pm 1 \mathrm{mmHg}, \quad P<0.005)$. The fall in systemic vascular resistance $(744 \pm 194$ vs $533 \pm 122$ dynes $\mathrm{s} \mathrm{cm}^{-5}$, NS) and pulmonary vascular resistance $\left(46 \pm 25\right.$ vs $58 \pm 31$ dynes $\mathrm{s} \mathrm{cm}^{-5}$, NS) was similar with the two drugs. Changes in heart rate and arterial mean pressure were not significantly different (NS). However, pulmonary arterial mean pressure fell more with prazosin $(7 \pm 1$ vs $3 \pm 2$ $\mathrm{mmHg}, \mathrm{P}<0.01)$. The increase in left ventricular stroke work was also similar $(4.05 \pm 2.28$ vs $5.67 \pm$ $2.01 \mathrm{~g} \mathrm{~m}$ per $\mathrm{m}^{2}$, NS), but arterial systolic pressureheart rate product decreased more with prazosin $(P<0.05)$. The effects of the oral vasodilators on the relation between filling pressure and stroke work also differed (Fig.).

\section{CLINICAL EFFECTS}

All patients tolerated treatment with nitroprusside and oral vasodilators without any major side effects during the study. With prazosin two patients had nausea initially which gradually disappeared. Two other patients developed mild headache while receiving hydralazine and required aspirin for relief. No episodes of hypotension, tachycardia, or myocardial ischaemia (angina or ST segments changes) were observed in any patient. In five patients, diastolic gallop disappeared and basal râles decreased with both prazosin and hydralazine.

\section{Discussion}

Our study was designed to compare the acute haemodynamic effects of one parenteral and two oral vasodilator agents in the same patients with heart failure. Baseline clinical evaluation and haemodynamic recordings were made after the systemic and pulmonary arterial pressures and cardiac output had become stable with bed rest. Prazosin and nitroprusside were given in random sequence; hydralazine was given last to all seven patients. Though a sufficient time interval was provided between the different agents to allow the pressures and cardiac output to return to baseline level, it is possible that the residual effect of one agent may possibly have affected the actions of another. The fixed doses of prazosin $(4 \mathrm{mg})$ and hydralazine $(100 \mathrm{mg})$ were selected after preliminary studies in other patients with variable dose regimens.

Our results support previous observations (Franciosa et al., 1972; Chatterjee et al., 1973a; Guiha et al., 1974) that intravenous nitroprusside produces haemodynamic improvement in patients with chronic heart failure: stroke work increases at a lower left ventricular filling pressure. In the same patients, orally administered prazosin (4 mg) resulted in a similar improvement in the relation between left ventricular filling pressure and stroke work, in association with a fall in systemic and pulmonary vascular resistance. Oral hydralazine $(100 \mathrm{mg})$ also increased stroke work with a decrease in systemic vascular resistance. Compared with prazosin and nitroprusside, the fall in left ventricular filling pressure with hydralazine was minimal.

Even in the same patient, the mechanism of action of the three vasodilators appeared to be different. Nitroprusside, by direct action, dilates both arterial and venous beds equally, resulting in a decrease in afterload as well as preload (Miller et al., 1976). Prazosin also has been shown to have a balanced dilator action on arterial and venous beds (Miller et al., 1977). The actions of prazosin are mediated by vascular alpha-receptor blockade (Graham and Pettinger, 1979). Because of their similar vasodilator effects, intravenous nitroprusside and oral prazosin have similar afterload- and preload-reducing effects in patients with congestive heart failure (Mehta et al., 1978a). Hydralazine, on the other hand, is a potent dilator of the arterial bed with only minimal effects on the venous bed (Franciosa et al., 1977). In addition, hydralazine has a positive inotropic action (Khatri et al., 1977). Because of the lack of a significant venodilator action, hydralazine administration does not decrease left ventricular filling pressure in patients with congestive heart failure, though systemic vascular resistance falls greatly (Chatterjee et al., 1976b; Franciosa et al., 1977; Mehta et al., 1978b). Our study shows that the decrease in afterload induced by the two oral vasodilators (prazosin and hydralazine) in the same patients is similar.

The exact mechanism of the increase in cardiac output after vasodilator therapy in patients with heart failure is not known. It has been suggested (Sonnenblick and Downing, 1963; Cohn, 1973) that cardiac output increases as a result of increased myocardial fibre shortening in the failing ventricle consequent upon vasodilator-induced reduction in systemic vascular resistance. Indeed, in this study, the high systemic vascular resistance associated with chronic heart failure fell with all three vasodilator agents. We have shown that in the failing heart, the pulsatile flow component (characteristic impedance) of the vascular load is increased (Pepine et al., 1978), in addition to the mean or steady flow component (systemic vascular resistance). These findings suggest that the compliance of the aorta is reduced in patients with heart failure. Preliminary studies in our laboratory show that in patients with 
heart failure nitroprusside decreases the pulsatile as well as the mean flow component of the vascular load (Pepine et al., 1975). These observations suggest that the beneficial action of nitroprusside may be related to altered aortic compliance (Pepine et al., 1975). The oral vasodilators compared in this study may also alter the distensibility of the aorta and thereby effect improved ventricular function by reducing the pulsatile component of vascular load. Inotropic actions of hydralazine (Khatri et al., 1977) may also be partly responsible for increased cardiac output. Whatever the precise mechanism of action in patients with heart failure both oral agents compared in this study improved left ventricular function. Furthermore, this haemodynamic improvement was observed at doses that were well tolerated in these patients.

Comparison of the haemodynamic effects of a single dose of oral prazosin $(4 \mathrm{mg})$ and of hydralazine $(100 \mathrm{mg}$ ) with nitroprusside in the same patients with heart failure showed that the effects of prazosin were similar to those of nitroprusside. In a given patient, prazosin, like nitroprusside, effectively decreased left ventricular filling and pulmonary arterial pressures and increased cardiac output. Left ventricular stroke work increased less with oral prazosin than with intravenous nitroprusside. This may be because of the greater effectiveness of nitroprusside or the dose of prazosin used (Mehta et al., 1978b). In contrast, oral hydralazine only increased cardiac output in the same patients. Though the increase in cardiac output was similar to that induced by prazosin, hydralazine caused no significant fall in left ventricular filling pressure. The absence of a significant fall in left ventricular filling and pulmonary arterial pressures with hydralazine may result from its lack of vasodilator effect on capacitance vessels (Chatterjee et al., 1976b; Franciosa et al., 1977; Mehta et al., 1978b). We (Mehta et al., 1978b) and others (Chatterjee et al., 1976a; Pierpont et al., 1978) have shown that a venodilator agent added to hydralazine lowers left ventricular filling pressure without altering cardiac output. Thus, hydralazine combined with a venodilator agent mimics the effects of intravenous nitroprusside; however, oral prazosin alone, like nitroprusside, improves left ventricular function.

Effective orally administered vasodilators are actively being sought for the management of ambulant patients with heart failure. This study shows that patients with the symptoms and signs of high left ventricular filling pressure and low cardiac output may benefit from the use of prazosin. On the other hand, hydralazine may be effective in those patients with low cardiac output but normal or only slightly increased left ventricular filling pressure.

\section{References}

Awan, N. A., Miller, R. R., DeMaria, A. N., Maxwell, K. S., Newmann, A., and Mason, D. T. (1977). Efficacy of ambulatory systemic vasodilator therapy with oral prazosin in chronic refractory heart failure. Circulation, 56, 346-354.

Bolen, J. L., and Alderman, E. L. (1976). Haemodynamic consequences of afterload reduction in patients with chronic aortic regurgitation. Circulation, 53, 879-883.

Chatterjee, K., Drew, D., Parmley, W., Klausner, S. C., Polansky, J., and Zacherle, B. (1976a). Combination vasodilator therapy for severe chronic congestive heart failure. Annals of Internal Medicine, 85, 467-470.

Chatterjee, K., and Parmley, W. W. (1977). The role of vasodilator therapy in heart failure. Progress in Cardiovascular Diseases, 19, 301-325.

Chatterjee, K., Parmley, W. W., Ganz, W., Forrester, J., Walinsky, P., Crexells, C., and Swan, H. J. C. (1973a). Hemodynamic and metabolic responses to vasodilator therapy in acute myocardial infarction. Circulation, 48, 1183-1193.

Chatterjee, K., Parmley, W. W., Massie, B., Greenberg, B., Werner, J., Klausner, S., and Norman, A. (1976b). Oral hydralazine therapy for chronic refractory heart failure. Circulation, 54, 879-883.

Chatterjee, K., Parmley, W. W., Swan, H. J. C., Berman, G., Forrester, J., and Marcus, S. H. (1973b). Beneficial effects of vasodilator agents in severe mitral regurgitation due to dysfunction of subvalvar apparatus. Circulation, 48, 684-690.

Cohn, J. N. (1973). Vasodilator therapy for heart failure: the influence of impedance on left ventricular performance. Circulation, 48, 5-8.

Franciosa, J. A., Guiha, N. H., Limas, C. J., Rodriguera, E., and Cohn, J. N. (1972). Improved left ventricular function during nitroprusside infusion in acute myocardial infarction. Lancet, 1, 650-654.

Franciosa, J. A., Mikulic, E., Cohn, J. N., Jose, E., and Fabie, W. (1974). Hemodynamic effects of orally administered isosorbide dinitrate in patients with congestive heart failure. Circulation, 50, 1020-1024.

Franciosa, J. A., Pierpont, G., and Cohn, J. N. (1977). Hemodynamic improvement after oral hydralazine in left ventricular failure. Annals of Internal Medicine, 86, 388-393.

Ganz, W., and Swan, H. J. C. (1972). Measurement of blood flow by thermodilution. American fournal of Cardiology, 29, 241-246.

Graham, R. M., and Pettinger, W. A. (1979). Drug therapy: prazosin. New England fournal of Medicine, 300, 232-236.

Guiha, N. H., Cohn, J. N., Mikulic, E., Franciosa, J. A., and Limas, C. J. (1974). Treatment of refractory heart failure with infusion of nitroprusside. New England fournal of Medicine, 291, 587-592.

Khatri, I., Uemura, N., Notargiacomo, A., and Freis, E. D. (1977). Direct and reflex cardiostimulating effects of hydralazine. American fournal of Cardiology, 40, 38-42.

Majid, P. A., Sharma, B., and Taylor, S. H. (1971). Phentolamine for vasodilator treatment for severe heart failure. Lancet, 2, 719-723.

Mantle, J. A., Russell, R. O., jun, Moraski, R. E., and Rackley, C. E. (1976). Isosorbide dinitrate for the relief of severe heart failure after acute myocardial infarction. American fournal of Cardiology, 37, 263-268.

Mehta, J., Iacona, M., Feldman, R. L., Pepine, C. J., and Conti, C. R. (1978a). Comparative hemodynamic effects of intravenous nitroprusside and oral prazosin in refractory heart failure. American fournal of Cardiology, 41, 925-930. 
Mehta, J., Pepine, C. J., and Conti, C. R. (1978b). Haemodynamic effects of hydralazine and of hydralazine plus glyceryl trinitrate paste in heart failure. British Heart fournal, 40, 845-850.

Miller, R. R., Awan, N. A., Maxwell, K. S., and Mason, E. T. (1977). Effect of prazosin on cardiac impedance and preload in congestive heart failure. New England fournal of Medicine, 297, 303-307.

Miller, R. R., Vismara, L. A., Williams, D. O., Amsterdam, E. A., and Mason, D. T. (1976). Pharmacological mechanism for ventricular unloading in clinical congestive heart failure: differential effects of nitroprusside, phentolamine and nitroglycerin on cardiac function and peripheral circulation. Circulation Research, 39, 127-133.

Pepine, C. J., Nichols, W. W., and Conti, C. R. (1978). Aortic input impedance in heart failure. Circulation, 58, 460-465.

Pepine, C. J., Nicholas, W. W., Curry, R. C., and Conti, C. R. (1975). Aortic input impedance during nitroprusside in- fusion. Reconsideration of afterload reduction and beneficial action (abstract). Circulation, 51 and 52, Suppl. II, 35.

Pierpont, G. L., Cohn, J. N., and Franciosa, J. A. (1978). Combined oral hydralazine-nitrate therapy in left ventricular failure. Chest, 73, 8-13.

Sonnenblick, E. H., and Downing, S. E. (1963). Afterload as a primary determinant of ventricular performance. American fournal of Physiology, 204, 604-610.

Winer, B. J. (1971). In Statistical Principles in Experimental Design, pp. 518-530. McGraw-Hill, New York.

Requests for reprints to Dr J. Mehta, Division of Cardiology, Department of Medicine, Box J-277, J. Hillis Miller Health Center, University of Florida, Gainesville, Florida 32610, USA. 